${ }^{1}$ Department of Internal Medicine, Medica Superspeciality Hospital, Kolkata, India

${ }^{2}$ Medical Scientific Liaison, Biocon India Pvt. Ltd, India

${ }^{3}$ Department of Internal Medicine, Narayana Superspeciality Hospital, West Bengal, India

\title{
A case study of eight type 2 diabetic stage 4 chronic kidney disease patients showing lower glycemic variability with faster-acting insulin aspart as compared to insulin aspart
}

\section{ABSTRACT}

Background. Peaks and nadirs of blood glucose level varying daily in a person is referred to as glycemic variability (GV). GV associated with diabetics has been recently linked to cardiovascular disorders (CVD) or even chronic kidney disease (CKD) progression. Faster-acting insulin aspart is the latest ultra-rapid acting bolus insulin which has shown much lesser intra- and inter-patient variability as compared to conventional bolus insulin. Material and methods. However, inadequate data exist regarding $\mathrm{GV}$ in patients with advanced stages of CKD. Hence, with this objective, the present case study was undertaken with eight patients divided into two equal groups, wherein faster-acting insulin aspart and insulin aspart were used as the boluses, respectively. Continuous glucose monitoring data of the patients were taken for the initial four days to calculate mean amplitude of glycemic excursion (MAGE) of the total four days for each individual $(\mathrm{mmol} / \mathrm{L})$ to see the difference in GV. A value of > $3.607 \mathrm{mmol} / \mathrm{L}(65 \mathrm{mg} / \mathrm{dL}$ ) was considered to be statistically significant.

Results. In this case study of eight stage 4 CKD type 2 diabetic patients, statistically significant lower GV

Address for correspondence:

Dr. Sayak Roy, MRCP (Ireland)

Department of Internal Medicine

Medica Superspeciality Hospital, Kolkata

West Bengal, 700027, India

Phone: +919051626890

e-mail: sayak.roy.123@gmail.com

Clinical Diabetology 2019, 8, 6, 284-291

DOI: $10.5603 /$ DK.2019.0027

Received: 18.09.2019

Accepted: 16.12.2019 was observed in the faster-acting insulin aspart arm when compared with the insulin aspart arm. The pvalue was $\mathbf{0 . 0 0 0 4}$ in unpaired t-test and $<0.05$ for $U$ in Mann-Whitney $U$ test after ruling out the baseline confounding factors.

Conclusions. This study confirms the stable pharmacokinetic and dynamic properties of faster-acting insulin aspart and subsequent studies with larger number of patients are required for a conclusive outcome. (Clin Diabetol 2019; 8, 6: 284-291)

Key words: type 2 diabetes mellitus, faster-acting insulin aspart, glycemic variability, mean amplitude of glucose excursion, chronic kidney disease, continuous glucose monitoring system

\section{Introduction}

Constant hyperglycemia and bursts of prandial glycemic surges can cause complications in diabetes mellitus (DM) as well as in stress hyperglycemia [1, 2]. Postprandial spikes in blood sugar, along with episodes of hypoglycemia, are responsible for an alarming increase in cardiovascular events in DM [2]. Glycemic variability (GV) comprises these events; thus, minimizing GV will suspend future cardiovascular events. Addressing GV emerges as a target to be pursued in clinical procedures to reduce the mean blood glucose, as GV is now considered to be an independent risk factor in diabetics for cardiovascular disease (CVD) [3]. Contemporary DM treatment modalities with glucagon-like peptide-1-based remedy, newer insulin, newer insulin pumps, bariatric surgery and newer oral anti-diabetic molecules considerably decrease GV [4]. 
The mean amplitude of glycemic excursion (MAGE) was intended to encapsulate repast-time related glucose excursions. GV implies to the swings in blood glucose level seen in a person daily. Decreased or missing glycemic auto-modulation or deficits of insulin accessibility are hypothesized to be the etiological causes for these glycemic ridges swings [4]. Intermittent high blood glucose exposure rather than constant high blood glucose exposure has been shown to have deleterious effect in various experimental studies [5].

GV indices derived from continuous glucose monitoring (CGM) are mean \pm standard deviation, J index, coefficient of variance, low blood glucose index, high blood glucose index, average daily risk range, MAGE, mean of daily differences and continuous overall net glycemic action [4].

Faster-acting insulin aspart is the latest ultra-rapid acting bolus insulin derived by substituting amino acid proline by aspartic acid in position B28 and adding inactive ingredients L-arginine, niacinamide and others and appearing in circulation after 2.5 minutes of administration [6]. But the data of this insulin in advanced chronic kidney disease (CKD) patients is limited, and therefore, the present case study was undertaken to get newer insights into the use of faster-acting insulin aspart as compared to insulin aspart in relation to the difference in MAGE, as MAGE or rather GV has been described as an independent marker of CVD [3].

\section{Case presentation}

We analyzed the clinical records of MAGE of eight type 2 diabetic CKD stage 4 (as calculated by Chronic Kidney Disease Epidemiology Collaboration equation) patients. A total data of thirty seven patients were searched who were meeting the primary criteria of basal-bolus insulin regimen with eGFR (estimated glomerular filtration rate) less than $30 \mathrm{ml} / \mathrm{min} / 1.73 \mathrm{~m}^{2}$ without any oral anti-diabetic drugs and out of them only eight finally meet the full inclusion criteria. All the patients had to meet the pre-specified inclusion criteria - type 2 diabetics who previously faced either severe or mild to moderate hypoglycemia on regular human insulin treatment, age more than 55 years; giving informed, written consent; MAGE calculated from CGM data; $\mathrm{HbA}_{1 \mathrm{c}}$ of 7.5-9\%; estimated glomerular filtration rate (eGFR) $15-30 \mathrm{ml} / \mathrm{min} / 1.73 \mathrm{~m}^{2}$; duration of diabetes for more than 10 years; all on basal-bolus insulin regimen (basal component being insulin glargine given at a dose to achieve a fasting value of $130 \mathrm{mg} / \mathrm{dl}$ ); no orally administered agents; and bolus was either insulin aspart or faster-acting insulin aspart given just before meals. The baseline characters of all patients are given in Table 1. Then they were divided into two groups

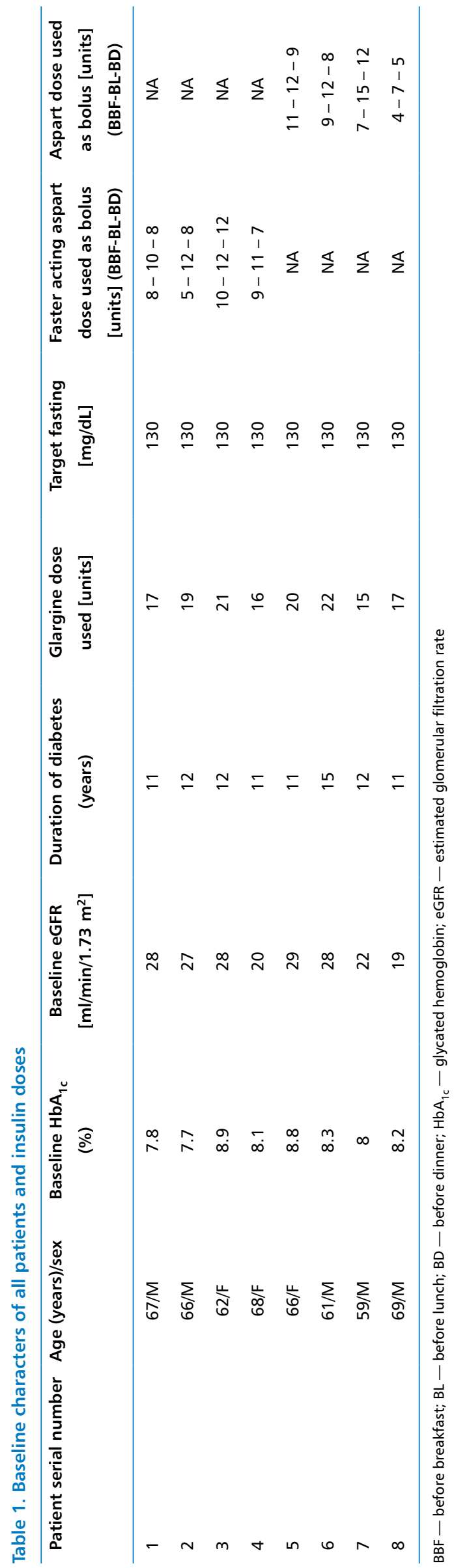


Table 2. 95\% confidence interval $(\mathrm{CI})$, standard deviation and mean values of baseline characters

\begin{tabular}{|c|c|c|c|c|c|}
\hline & $\begin{array}{c}\text { MAGE } \\
{[\mathrm{mmol} / \mathrm{L}]}\end{array}$ & $\begin{array}{c}\mathrm{HbA}_{1 \mathrm{c}} \\
(\%)\end{array}$ & $\begin{array}{c}\text { eGFR } \\
{\left[\mathrm{ml} / \mathrm{min} / 1.73 \mathrm{~m}^{2}\right]}\end{array}$ & $\begin{array}{c}\text { Duration of } \\
\text { diabetes (years) }\end{array}$ & $\begin{array}{c}\text { Age } \\
\text { (years) }\end{array}$ \\
\hline Standard deviation, $\delta$ & 1.37 & 0.40 & 3.82 & 1.26 & 3.38 \\
\hline $95 \% \mathrm{Cl}$ & $\begin{array}{l}4.87 \pm 0.95 \\
( \pm 19.60 \%)\end{array}$ & $\begin{array}{c}8.22 \pm 0.28 \\
( \pm 3.42 \%)\end{array}$ & $\begin{array}{c}25.12 \pm 2.64 \\
( \pm 10.54 \%)\end{array}$ & $\begin{array}{c}11.87 \pm 0.87 \\
( \pm 7.40 \%)\end{array}$ & $\begin{array}{c}64.75 \pm 2.34 \\
( \pm 3.62 \%)\end{array}$ \\
\hline Average (mean values) & 4.87 & 8.22 & 25.12 & 11.87 & 64.75 \\
\hline
\end{tabular}

MAGE — mean amplitude of glucose excursion; $\mathrm{HbA}_{1 c}$ - glycated hemoglobin; eGFR — estimated glomerular filtration rate

depending on the types of hypoglycemia faced by each patient namely those with severe hypoglycemia were treated with faster-acting aspart insulin and those who had mild to moderate hypoglycemia were treated with aspart insulin as the bolus insulin. The mean baseline values of the total population were $\mathrm{HbA}_{1 \mathrm{c}} 8.22 \%$, age 64.75 years, duration of diabetes 11.87 years and eGFR $25.12 \mathrm{ml} / \mathrm{min} / 1.73 \mathrm{~m}^{2}$. The $95 \%$ confidence interval (CI) and standard deviation (SD) values of the above baseline characters are given in Table 2.

\section{Materials and methods}

In the present case study, we analyzed the CGM data (performed with Medtronic iPro ${ }^{\circledR}$ machine) of the patients for the initial four days to calculate MAGE (mmol/L) for each individual as measured by the software EasyGV Version 9.0.R2 (Nathan R Hill Copyright University of Oxford 2010-2016) so as to see the differences in GV. A value of more than 3.607 $\mathrm{mmol} / \mathrm{L}$ (65 $\mathrm{mg} / \mathrm{dL}$ ) was considered to be significantly high, indicating high GV as has been found previously [7]. All the methods were followed as per directions laid down in the declaration of Helsinki.

A CGM sensor was attached to the subcutaneous fat tissue of these patients and adjusted by the standard Medtronic iPro2 working principles. While wearing the CGM, the patients checked their blood glucose levels with a self-monitoring blood glucose device, 4 times a day. The data of the first 4 days from the CGM of each patient was analyzed with the above-mentioned software to calculate MAGE as well as eight other GV indices, namely SD, mean, continuous overall net glycemic action, mean of daily differences, average daily risk range, J index, low blood glucose index and high blood glucose index. After analyzing data, patients were divided into two groups (4 patients each). The first group used only aspart as bolus insulin while the other group used faster-acting aspart as bolus insulin. Unpaired T-test and Mann-Whitney U-test were applied to compare the two groups with regard to each parameter that could have affected the final MAGE outcome, namely baseline $\mathrm{HbA}_{1 \mathrm{c}^{\prime}}$ age, duration of diabetes, and eGFR. Baseline Pearson correlation and Spearman Rank correlation were also calculated [software: Wessa P. (2017). Pearson Correlation (v1.0.13) in (Free Statistics Software (v1.2.1), Office for Research Development and Education] was used to determine any baseline statistical significance which might affect the MAGE (as MAGE was the dependable variable here).

\section{Results}

The baseline correlation equations using both Pearson's formula and Spearman Rank formula (Table 3) confirm no statistical significance with MAGE as dependable variable. Here, the independent variables were $\mathrm{HbA}_{1 \mathrm{c}}$ ( $\mathrm{p}$-value 0.347 for Pearson formula), age ( $p$-value 0.344 for Pearson formula), duration of diabetes ( $p$-value 0.188 for Pearson formula) and eGFR ( $p$-value 0.79 for Pearson formula).

After dividing the MAGE calculated and other GV parameters calculated in two groups, we applied Unpaired T-test and Mann-Whitney $U$ test (Table 4) to see the baseline statistical differences between the two groups in terms of $\mathrm{HbA}_{1 c^{\prime}}$ age, duration of diabetes and eGFR which might have affected the final MAGE outcome. We found all the parameters to be statistically non-significant in both the tests, reducing the bias at baseline parameters for the outcome.

Further, on applying Unpaired T-test and Mann-Whitney $U$ test in MAGE outcome (Table 5) and Unpaired T-test on other eight GV parameters (Table 6) between the two groups, only MAGE showed statistically significant results in Unpaired T-test ( $p$-value 0.0004 ) as well as in Mann-Whitney $U$ test ( $p$-value 0.012).

As SD between groups can cause significant changes in the MAGE outcome, we also performed both Unpaired T-test and Mann-Whitney U-test between the two groups taking their SD values (Table 7) and found both to be statistically non-significant, ruling out the probability of SD to be a confounding factor in the final MAGE outcome analysis between the two groups.

The figures of CGM data of one patient from each group are given in Figure 1 and Figure 2 and also the 
Table 3. Correlation analysis for MAGE as dependable variable against independent variables duration of diabetes, $\mathrm{HbA}_{1 \mathrm{c}^{\prime}}$ age and eGFR

\begin{tabular}{|c|c|c|c|c|}
\hline Pearson correlation (dependable variable MAGE) & $\mathrm{HbA}_{1 \mathrm{c}}$ & eGFR & Age & $\begin{array}{c}\text { Duration of } \\
\text { diabetes }\end{array}$ \\
\hline T-test & 1.01 & -0.27 & -1.02 & 1.48 \\
\hline p-value ( 2 sided) & 0.34 & 0.79 & 0.34 & 0.18 \\
\hline $95 \% \mathrm{Cl}$ of correlation & {$[-0.43,0.85]$} & {$[-0.75,0.64]$} & {$[-0.85,0.43]$} & {$[-0.29,0.89]$} \\
\hline \multicolumn{5}{|l|}{$\begin{array}{l}\text { Spearman rank correlation } \\
\text { (dependable variable MAGE) }\end{array}$} \\
\hline Rho & 0.54 & 0.17 & -0.35 & 0.18 \\
\hline 2-sided p-value & 0.17 & 0.68 & 0.38 & 0.66 \\
\hline
\end{tabular}

MAGE - mean amplitude of glycemic excursions; $\mathrm{HbA}_{1 \mathrm{c}}$ - glycated hemoglobin; eGFR — estimated glomerular filtration rate; $\mathrm{Cl}$ - confidence interval

average CGM values of each group is described in Table 8 which also shows no significant difference between the average CGM values between two groups.

\section{Discussion}

The postprandial glycemic excursions in glucose level, as well as daily glucose variations, lead to GV [4]. The event of different microvascular and macrovascular complications in diabetes is ascribed to the dysglycemia (peaks and nadirs) seen in a diabetic patient occurring more than the accepted physiological variations for that individual [8]. Two unifying hypotheses have been put forward that accounts for GV, uncontrolled protein glycation termination products and initiation of oxidative stress, resulting in vascular complications [4]. There is a significant relationship between GV and the increased occurrence of hypoglycemia [9]. $\mathrm{HbA}_{1 \mathrm{c}}$ reflects only $8 \%$ of severe hypoglycemia; hence, it is a poor marker [10]. But GV can predict around 40 to $50 \%$ of future hypoglycemic episodes [4]. Investigations have demonstrated that GV, related to extreme hypoglycemia, could be deleterious to both diabetics as well as non-diabetic patients in intensive care units [11]. Besides CVD, the risk of retinopathy is also increased with GV. The contribution of GV and instability rather than the absolute glucose values have been shown to be responsible for CV mortality as well as for all-cause mortality in elderly type 2 DM patients [12]. Additionally, in 1504 acute ischemic stroke patients with diabetes, it was observed that even after adjusting baseline $\mathrm{HbA}_{1 \mathrm{c}^{\prime}}$ the functional outcome after 3 months was poorer in patients having increasing glucose level range quartile (used as GV marker). CKD has been shown to be a major contributor to GV [13].

Among the various methods used to determine GV, MAGE is an acceptable tool, but it has some disadvantages, e.g., connection with SD with the presentation of CGM, postprandial excursions can be surveyed using the zone under the curve and the trapezoidal strategy; the determination of MAGE is operator-controlled and not unambiguously characterized [14]. Among non-diabetic patients having coronary artery disease (CAD), MAGE was found to be associated with cardiovascular events [7]. However, in type 2 diabetic patients, MAGE, as one of the GV parameter, was found to be significantly associated with CAD, CKD and stroke(p-value for all three $<0.01)$. MAGE also showed significant correlation to eGFR and urine albumin:creatinine ratio ( $p$-value for both < 0.03) [15].

Faster-acting insulin aspart is the fastest ultra-rapid acting bolus insulin derived by substituting an amino acid from the regular insulin chain at B28 position by aspartic acid with the addition of few ingredients like L-arginine and niacinamide. It reaches bloodstream by 2.5 minutes with stable pharmacokinetic and pharmacodynamic properties and is suitable for use even post-meals for prandial control of glucose [6]. Niacinamide causes faster absorption of the insulin from subcutaneous tissue [6]. The data of this insulin in stage 4 CKD patients is sparse, and therefore, the present case study has provided some insight into this aspect. However, larger trials are required for further inference. Another switchover study on faster-acting insulin aspart showed significant reduction in nocturnal hypoglycemia risk when compared to human regular insulin by $80 \%$ as well as significant reduction in MAGE value over four days [16]. Due to the ultra-rapid onset of action, the risk seems to be reduced for hypoglycemia [17] as well there is documented $74 \%$ greater early glucose reductions when compared to aspart insulin [18]. These properties of faster-acting aspart make it an ideal candidate to lower GV with least risk of hypoglycemia when compared to aspart insulin. 
Table 4. Unpaired T-test and Mann-Whitney $U$ test between various parameters that might affect the MAGE outcome between two groups (one using faster-acting insulin aspart and the other using insulin aspart)

\begin{tabular}{|c|c|c|c|c|}
\hline Unpaired T-test for $\mathrm{B} / \mathrm{L} \mathrm{HbA}{ }_{1 \mathrm{c}}$ & Mean & SD & $95 \% \mathrm{Cl}$ & p-value \\
\hline Faster-acting-aspart group & 8.12 & 0.54 & -0.58 to 0.98 & 0.55 \\
\hline Aspart group & 8.32 & 0.34 & & \\
\hline \multicolumn{5}{|l|}{ Unpaired T-test for B/L eGFR } \\
\hline Faster-acting-aspart group & 25.75 & 3.86 & -8.78 to 6.28 & 0.69 \\
\hline Aspart group & 24.5 & 4.8 & & \\
\hline \multicolumn{5}{|l|}{ Unpaired T-test for $B / L$ age } \\
\hline Faster-acting-aspart group & 65.75 & 2.63 & -8.45 to 4.45 & 0.47 \\
\hline Aspart group & 63.75 & 4.57 & & \\
\hline \multicolumn{5}{|c|}{ Unpaired T-test for $\mathrm{B} / \mathrm{L}$ duration of diabetes } \\
\hline Faster-acting-aspart group & 11.5 & 0.58 & -1.67 to 3.17 & 0.47 \\
\hline Aspart group & 12.25 & 1.89 & & \\
\hline Mann-Whitney U-test & For $\mathrm{HbA}_{1 \mathrm{c}}$ & For age & For EGFR & For duration of diabetes \\
\hline $\mathrm{U}$ value & 7 & 8.5 & 11 & 9 \\
\hline Critical value of $U$ at $p<0.5$ & 2 & 2 & 2 & 2 \\
\hline Statistical significance of $U$ & Non significant & Non significant & Non significant & Non significant \\
\hline Z-score & 1.04 & 0.73 & -0.20 & -0.62 \\
\hline$p$-value of $Z$ & 0.29 & 0.46 & 0.83 & 0.52 \\
\hline Statistical significance of Z-score & Non significant & Non significant & Non significant & Non significant \\
\hline
\end{tabular}

$\mathrm{HbA}_{1 \mathrm{c}}$ - glycated hemoglobin; eGFR - estimated glomerular filtration rate; SD — standard deviation; $\mathrm{Cl}$ - confidence interval

Table 5. Unpaired T-test values and Mann-Whitney U test for MAGE values of the two groups

\begin{tabular}{|c|c|c|c|c|}
\hline Unpaired T-test & Mean & SD & $95 \% \mathrm{Cl}$ & p-value \\
\hline Faster-acting insulin aspart group & 3.66 & 0.63 & 1.47 to 3.38 & $0.0004^{*}$ \\
\hline Insulin aspart group & 6.08 & 0.66 & & \\
\hline \multicolumn{5}{|l|}{ Mann-Whitney U-test } \\
\hline$U$ value & & & 0 & \\
\hline Critical value of $U$ at $p<0.5$ & & & 2 & \\
\hline Statistical significance of $U$ & & & Significant & \\
\hline Z-score & & & 2.50 & \\
\hline$p$-value of $Z$ & & & $0.01 *$ & \\
\hline Statistical significance of Z-score & & & Significant & \\
\hline
\end{tabular}

*Extremely statistically significant for unpaired T-test and statistically significant for Mann-Whitney U test; Cl — confidence interval; SD — standard deviation; MAGE - mean amplitude of glucose excursion

Our case study revealed that faster-acting insulin aspart (as compared to insulin aspart) had a lower GV, indicated by MAGE outcome from CGM in advanced stage 4 CKD diabetic patients, even after excluding confounding factors of baseline $\mathrm{HbA}_{1 c^{\prime}}$ age, duration of diabetes, eGFR and SD between the two groups as projected by the $p$-values of 0.0004 in unpaired t-test and $<0.05$ for $U$ in Mann-Whitney $U$ test. Hence, faster-acting insulin aspart can be used therapeutically to achieve acceptable GV in most diabetic patients with
CKD, as it showed better results in patients in stage 4 of CKD. Lower GV should clinically produce lower rates of hypoglycemic risk, which should be our target to effectively counter glycemia in advanced CKD patients.

\section{Conclusion}

In this case study, we found that faster-acting insulin aspart was associated with statistically significant lower GV, as compared to insulin aspart, in patients 
Table 6. Unpaired T-test of glycemic variability parameters other than MAGE in two groups

\begin{tabular}{|c|c|c|c|c|}
\hline & Mean & SD & $95 \% \mathrm{Cl}$ & p-value \\
\hline \multicolumn{5}{|l|}{ SD } \\
\hline Faster-acting insulin aspart & 2.34 & 0.74 & -0.89 to 0.93 & 0.96 \\
\hline Insulin aspart & 2.36 & 0.08 & & \\
\hline \multicolumn{5}{|l|}{ Mean } \\
\hline Faster-acting-aspart group & 8.58 & 0.64 & -0.79 to 1.48 & 0.48 \\
\hline Aspart group & 8.92 & 0.67 & & \\
\hline \multicolumn{5}{|c|}{ Continuous overall net glycemic action } \\
\hline Faster-acting-aspart group & 8.10 & 0.44 & -1.37 to 1.02 & 0.73 \\
\hline Aspart group & 7.93 & 0.87 & & \\
\hline \multicolumn{5}{|l|}{ High blood glucose index } \\
\hline Faster-acting-aspart group & 6.94 & 2.28 & -2.93 to 3.30 & 0.88 \\
\hline Aspart group & 7.13 & 1.13 & & \\
\hline \multicolumn{5}{|l|}{ Average daily risk range } \\
\hline Faster-acting-aspart group & 16.43 & 4.84 & -0.33 to 12.8 & 0.05 \\
\hline Aspart group & 22.66 & 2.32 & & \\
\hline \multicolumn{5}{|l|}{$J$ index } \\
\hline Faster-acting-aspart group & 38.90 & 6.74 & -7.72 to 12.68 & 0.57 \\
\hline Aspart group & 41.38 & 4.90 & & \\
\hline \multicolumn{5}{|l|}{ Low blood glucose index } \\
\hline Faster-acting-aspart group & 0.89 & 0.29 & -0.90 to 1.35 & 0.64 \\
\hline Aspart group & 1.11 & 0.87 & & \\
\hline \multicolumn{5}{|l|}{ Mean of daily differences } \\
\hline Faster-acting-aspart group & 2.31 & 0.65 & -1.51 to 0.23 & 0.12 \\
\hline Aspart group & 1.67 & 0.28 & & \\
\hline
\end{tabular}

$\mathrm{SD}$ - standard deviation; $\mathrm{Cl}$ - confidence interval

Table 7. Unpaired T-test and Mann-Whitney U-test between the two groups for SD

\begin{tabular}{|c|c|c|c|c|}
\hline Unpaired T-test & Mean & SD & $95 \% \mathrm{Cl}$ & p-value \\
\hline Faster-acting insulin aspart group & 42.18 & 13.41 & 16.19 to 16.83 & 0.96 \\
\hline Insulin aspart group & 42.50 & 1.47 & & \\
\hline \multicolumn{5}{|l|}{ Mann-Whitney U-test } \\
\hline$U$ value & & & 7 & \\
\hline Critical value of $U$ at $p<0.5$ & & & 2 & \\
\hline Statistical significance of $U$ & & & Non significant & \\
\hline Z-score & & & 1.04 & \\
\hline$p$-value of $Z$ & & & 0.29 & \\
\hline Statistical significance of Z-score & & & Non significant & \\
\hline
\end{tabular}

$\mathrm{SD}$ - standard deviation; $\mathrm{Cl}$ - confidence interval 


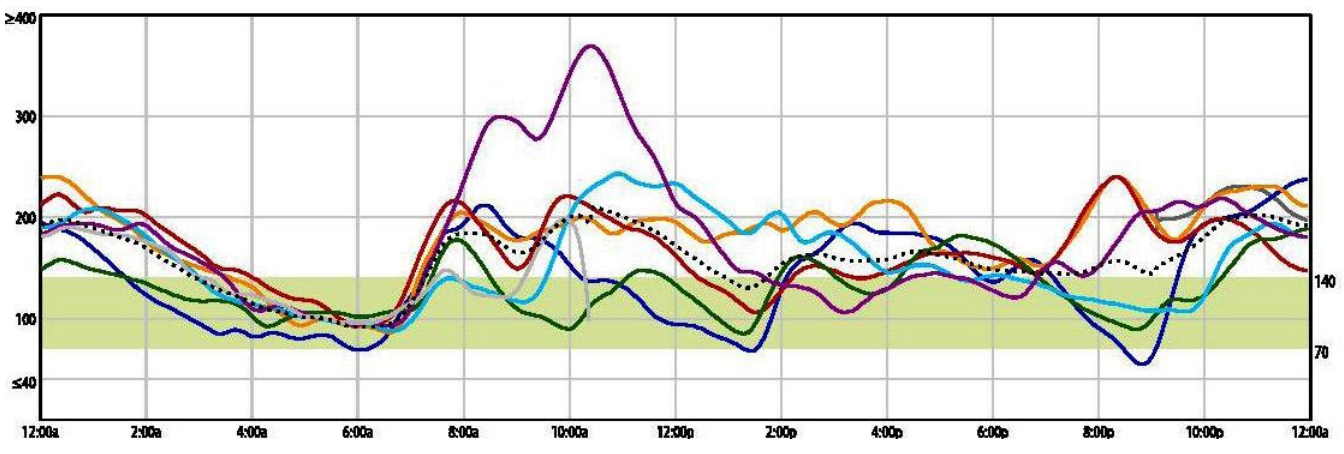

Figure 1. CGM data of one patient on aspart insulin

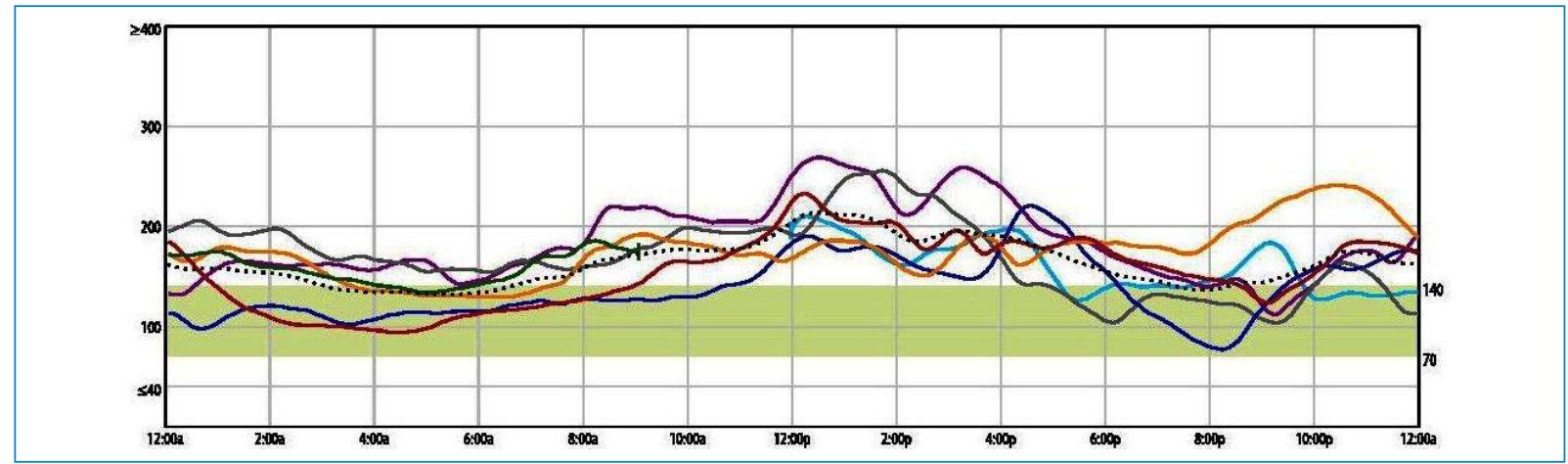

Figure 2. CGM data of one patient on faster-acting aspart insulin

Table 8. CGM values averaged over the four days in two groups

\begin{tabular}{lccc}
\hline Patient serial number & CGM value averaged for four days & Bolus insulin group & Average value of CGM for each group \\
\hline 1 & 156.21 & Faster-acting aspart & 160.66 \\
& & group & \\
3 & 160.32 & & \\
4 & 177.33 & Aspart group & \\
5 & 148.79 & & \\
6 & 163.47 & & \\
7 & 138.85 & & \\
8 & 162.91 & & \\
\hline
\end{tabular}

with advanced CKD. Recently, GV has emerged as a target objective in diabetes holistic management due to its association with CVD and CKD progression. Finally, this study confirms the stable pharmacokinetic and dynamic properties of faster-acting insulin aspart, and future studies involving larger number of patients can help draw a conclusion.

\section{Ethics committee approval}

Not required, as it is a case study where patients gave proper informed written consent to use their clini- cal medical records, without exposing their identity, for academic purposes in medical field.

\section{Informed consent}

Written informed consent was taken from all the participants.

\section{Acknowledgment}

The authors would like to acknowledge the contribution of Mr. Dinu Surendran of India Medtronic Pvt. $\mathrm{Ltd}^{\circledR}$ in calculating MAGE. 


\section{Author contributions}

All authors certify that they have participated adequately in developing intellectual content and analysis of data. Each author has reviewed the final version of the manuscript and approves it for publication.

\section{REFERENCES}

1. Dungan KM, Braithwaite SS, Preiser JC. Stress hyperglycaemia. Lancet. 2009; 373(9677): 1798-1807, doi: 10.1016/S01406736(09)60553-5, indexed in Pubmed: 19465235.

2. Cavalot F, Pagliarino A, Valle M, et al. Postprandial blood glucose predicts cardiovascular events and all-cause mortality in type 2 diabetes in a 14-year follow-up: lessons from the San Luigi Gonzaga Diabetes Study. Diabetes Care. 2011; 34(10): 2237-2243, doi: 10.2337/dc10-2414, indexed in Pubmed: 21949221.

3. Sartore G, Chilelli NC, Burlina S, et al. The importance of HbA1c and glucose variability in patients with type 1 and type 2 diabetes: outcome of continuous glucose monitoring (CGM). Acta Diabetol. 2012; 49 Suppl 1: S153-S160, doi: 10.1007/s00592-012-0391-4, indexed in Pubmed: 22466072.

4. Suh S, Kim JH. Glycemic Variability: How Do We Measure It and Why Is It Important? Diabetes Metab J. 2015; 39(4): 273-282, doi: 10.4093/dmj.2015.39.4.273, indexed in Pubmed: 26301188.

5. Satya Krishna SV, Kota SK, Modi KD. Glycemic variability: Clinical implications. Indian J Endocrinol Metab. 2013; 17(4): 611-619, doi: 10.4103/2230-8210.113751, indexed in Pubmed: 23961476.

6. Fiaspinsulin aspart injection 100 units/mL.Fiasp. 2018;1-12. Available at: https://www.novo-pi.com/fiasp.pdf.

7. Akasaka T, Sueta D, Tabata N, et al. Effects of the Mean Amplitude of Glycemic Excursions and Vascular Endothelial Dysfunction on Cardiovascular Events in Nondiabetic Patients With Coronary Artery Disease. J Am Heart Assoc. 2017; 6(5), doi: 10.1161/ JAHA.116.004841, indexed in Pubmed: 28446494.

8. Stratton IM, Adler Al, Neil HA, et al. Association of glycaemia with macrovascular and microvascular complications of type 2 diabetes (UKPDS 35): prospective observational study. BMJ. 2000; 321(7258): 405-412, doi: 10.1136/bmj.321.7258.405, indexed in Pubmed: 10938048.

9. Jeha GS, Karaviti LP, Anderson B, et al. Insulin pump therapy in preschool children with type 1 diabetes mellitus improves gly- cemic control and decreases glucose excursions and the risk of hypoglycemia. Diabetes Technol Ther. 2005; 7(6): 876-884, doi: 10.1089/dia.2005.7.876, indexed in Pubmed: 16386093.

10. Hypoglycemia in the diabetes control and complications trial. The Control and Complications Trial Research Group. Diabetes. 1997; 46(2): 271-286, doi: 10.2337/diab.46.2.271.

11. Eslami S, Taherzadeh Z, Schultz MJ, et al. Glucose variability measures and their effect on mortality: a systematic review. Intensive Care Med. 2011; 37(4): 583-593, doi: 10.1007/s00134010-2129-5, indexed in Pubmed: 21279326.

12. Muggeo $M$, Verlato $G$, Bonora $E$, et al. Long-term instability of fasting plasma glucose, a novel predictor of cardiovascular mortality in elderly patients with non-insulin-dependent diabetes mellitus: the Verona Diabetes Study. Circulation. 1997; 96(6): 1750-1754, doi: 10.1161/01.cir.96.6.1750, indexed in Pubmed: 9323057.

13. Kim YS, Kim $\mathrm{C}$, Jung $\mathrm{KH}$, et al. Range of glucose as a glycemic variability and 3-month outcome in diabetic patients with acute ischemic stroke. PLoS One. 2017; 12(9): e0183894, doi: 10.1371/ journal.pone.0183894, indexed in Pubmed: 28880933.

14. DeVries JH. Glucose variability: where it is important and how to measure it. Diabetes. 2013; 62(5): 1405-1408, doi: 10.2337/ db12-1610, indexed in Pubmed: 23613566.

15. Tong $L$, Chi C, Zhang Z. Association of various glycemic variability indices and vascular outcomes in type-2 diabetes patients: A retrospective study. Medicine (Baltimore). 2018; 97(21): e10860, doi: 10.1097/MD.0000000000010860, indexed in Pubmed: 29794785.

16. Roy S, Bera M, Bhattacharya G, et al. Switch-over study with fast-acting insulin aspart showing lower glycemic variability in type 2 diabetics with stage 4 chronic kidney disease: a case series. Cureus. 2019; 11(12): e6344, doi: 10.7759/cureus.6344, indexed in Pubmed: 31886089.

17. De Block C, Carlson A, Rose L, et al. Hypoglycemia with mealtime fast-acting insulin aspart vs. Insulin aspart across two large type 1 diabetes trials. Diabetes. 2018; 67 Suppl 1, doi: 10.2337/ db18-96-lb.

18. Heise T, Pieber TR, Danne T, et al. A pooled analysis of clinical pharmacology trials investigating the pharmacokinetic and pharmacodynamic characteristics of fast-acting insulin aspart in adults with type 1 diabetes. Clin Pharmacokinet. 2017; 56(5): 551-559, doi: 10.1007/s40262-017-0514-8, indexed in Pubmed: 28205039. 